\title{
A Multiband Arrow Shaped Patch Antenna Based on Apollonian Gasket and Soddy's circle for application in LTE and UWB range
}

\author{
Anurima Majumdar, Sisir Kumar Das, Annapurna Das
}

\begin{abstract}
A novel arrow shaped planar multiband antenna based on apollonian gasket and Soddy's circle with Defective Ground Structure (DGS) is described in this paper. The structure is designed on an FR4_epoxy substrate ( $\left.\varepsilon_{r}=4.4\right)$. The performance is evaluated using HFSS software. The antenna displays multiband behaviour in the frequency range from 3 to $10 \mathrm{GHz}$ which is suitable for wireless communications applications. The antenna gives tri-frequency response in LTE range $600 \mathrm{MHz}$ $6 \mathrm{GHz}): 1.17 \mathrm{GHz}, 3.44 \mathrm{GHz}$ and $6 \mathrm{GHz}$;and tetra frequency response in the UWB frequency range $(3 \mathrm{GHz}$ to $10 \mathrm{GHz}): 8.1$ $\mathrm{GHz}, 9.5 \mathrm{GHz}, 11.8 \mathrm{GHz} \& 13.5 \mathrm{GHz}$ which could be used in wireless and radar communications.The overall performance of the antenna demonstrates an average impedance bandwidth(IBW) of $300 \mathrm{MHz}$ with a good impedance matching $\left(\begin{array}{lll}S 11<-10 & d B\end{array}\right)$.The proposed antenna has the satisfactory radiation characteristics throughout its operating band. The measured highest gain differs from $1 \mathrm{dBi}$ to $1.9 \mathrm{dBi}$ inthe entire frequency range.
\end{abstract}

Keywords: Arrow shaped antenna, apollonian gasket, Soddy's circle, multiband, defected ground structure (DGS), microstrip patch antenna (MPA)

\section{INTRODUCTION}

Due to the rapid advancement in communication technology the demand of more efficient devices has rose to a significant peak. Many new techniques are being followed while designing microstrip patch antenna to operate with these devices over a wide frequency range. One of them is use of Defective Ground Structure (DGS). As reported by researchers integrating DGS to antenna improves radiation characteristics. Kim and Park [1] first anticipated and used the term 'DGS' in describing a Defect in the ground plane by introducing a dumbbell shape unit. Since then it has been exploited for better performance of the microstrip antenna by many authors. Introduction of slots in ground plane is a very efficient process to obtain desired performance of a printed microstrip antenna. Mark et al [2] proposed a fractal antenna with hexagonal-ring elementswhich yields 5 resonant frequencies. Biswas et al[3] reported a dual band printed antenna that resonated at 2.4 and $5.8 \mathrm{GHz}$ for the application of in WLAN/Wi-Fi.

Revised Manuscript Received on December 30, 2019.
* Correspondence Author

Anurimam Majumdar, Department of Electronics.\& Communication.Engineering(ECE), Guru. Nanak Institute of Technology(GNIT) JIS Group, KolkataA, 700114, India SisirkKumar Das, Department of Electronics.\& Communication.Engineering(ECE), Guru. Nanak Institute of Technology(GNIT) JIS Group, KolkataA, 700114, India Annapurnaa Das, Department of Electronics.\& Communication.Engineering(ECE), Guru. Nanak Institute of Technology(GNIT) JIS Group, KolkataA, 700114, India

(c) The Authors. Published by Blue Eyes Intelligence Engineering and Sciences Publication (BEIESP). This is an open access article under the CC BY-NC-ND license (http://creativecommons.org/licenses/by-nc-nd/4.0/)
Naik et al [4] reported a design of a hex-decagonshaped circular microstrip antenna operating at two resonating frequencies $13.67 \mathrm{GHz}, 15.28 \mathrm{GHz}$ with return loss better than $35 \mathrm{~dB}$. Impedance bandwidths of $854 \mathrm{MHz}$ and $1140 \mathrm{MHz}$, respectively are also required. Patel et al[5] proposed a compact size triple-band antenna for Wireless ISM and RFID applications resonating at $926 \mathrm{MHz}$ , $1.57 \mathrm{GHz} \& 2.47 \mathrm{GHz}$.IBW of $20 \mathrm{MHz}(913-934 \mathrm{MHz})$, $90 \mathrm{MHz}(1.5-1.59 \mathrm{GHz})$ and70MHz $(2.43-2.50 \mathrm{GHz})$ are obtained for the proposed range. Authors have reported many techniques to obtain multifrequency operation like crinkle fractal-structure, square spiral structure etc [6-9]. The microstrip antenna configuration with combination of gap-couplingand multilayer stacking has been reportedby Sun et.al [10]to work in multiband andbroadband range. Kiruthikaet al [11] presents a compact size, dual band antennawhich operates at two frequencies at $9.19 \mathrm{GHz}$ and $10.85 \mathrm{GHz}$ respectively. This antenna yields $600 \mathrm{MHz}$ (6.53\%) and $1650 \mathrm{MHz}$ (15.20\%) IBWat these frequencies.Khandelwal et al [12] presented the evaluation of DGS through analysis and simulation. They discussed the role of DGS in the field of microwave andmicrostrip antennas with various applications, that is,shrinking, multibandperformance, bandwidthimprovement, gain improvement, suppression of mutualcouplingbetween two elements, suppression of higher mode harmonics, reduction of cross-polarization.Fernandez et al [13] described a design of multi-frequency patch antenna using DGS for C band and $\mathrm{X}$ band operations. Because of the use of DGS the antenna produced resonant frequencies at $4.4 \mathrm{GHz}, 6.3 \mathrm{GHz}, 8.1 \mathrm{GHz}$ and $8.8 \mathrm{GHz}$ and rejection band $4.4-6.2 \mathrm{GHz}$ for WLAN applications, $6.5-8.0 \mathrm{GHz}$ for satellite downlink and uplink applications, 8.2 - $8.8 \mathrm{GHz}$ for ITU and $8 \mathrm{GHz}$ in X Band. R.Er-rebyiy et al [14] settled a new observation concerning the size reduction of microstrip patch antenna by using DGS resonating at $3.5 \mathrm{GHz}$. By using DGS the operating frequency was shifted to lower frequenct. Singh et.al [15] reported a Sectored annular ringmicrostrip antenna with DGS for circular polarization with $34.61 \%$ impedance bandwidth at $2.6 \mathrm{GHz}$ and $6.96 \mathrm{~dB}$ peak gain. Usage of Apollonian gasket geometry is also a new technique which is used by many authors for fractal geometry [1619].Kumaret.al [20] presented a design of Appolliangasket like CPW-fed fractal antenna. The antenna was reported to be showing multiband behaviour with resonating frequencies at $1.265,4.66$, and $7.8 \mathrm{GHz}$ with IBW of $50 \%$, $17 \%$, and $15 \%$, respectively.Rao et al [21] proposed a Smith-Apollonian Gasket (SAG) fractaldesign for microstrip patch antenna that has a multibandbehaviour in the frequency range from $3 \mathrm{GHz}$ to $10 \mathrm{GHz}$ with frequency peaks at $4.5 \mathrm{GHz}, 5.5$ 


\section{A Multiband Arrow Shaped Patch Antenna Based on Apollonian Gasket and Soddy's circle for application in LTE and UWB range}

GHz, 7.5 GHz and 9.0 GHz. Guha et al [22] discussed about the recent trends, applications and advantages of using DGS in microstrip antennas.Manyother authors [23-31] discussed, analysed and established the basic fundamentals of the design of apollonian gasket and Soddy's circle.

In this article a new structure of MPAwith DGS is proposed for multiband operation.The structure is fabricated on an FR4_epoxy dielectric substrate $\left(\varepsilon_{\mathrm{r}}=4.4\right)$ having thickness of $1.6 \mathrm{~mm}$ and a loss tangent of 0.02 . This design produces multiband operation with an acceptable gain. From the literature survey it is evident that different mathematical models may be used to design the configuration of the slots on the patch which along with the DGS may result in better performance. In this design an arrow shaped microstrip patch antenna is configured using apollonian gasket with the concept of Soddy's circleas shown in Figure 1(a). A rectangular window is used on the ground plane as DGS. Ansoft HFSS is used to simulate the proposed structure. The antenna produceshepta-frequency response at frequencies $1.17 \mathrm{GHz}, 3.44 \mathrm{GHz}, 6 \mathrm{GHz}, 8.1 \mathrm{GHz}, 9.5 \mathrm{GHz}, 11.8 \mathrm{GHz}$ \& $13.5 \mathrm{GHz}$ with $\mathrm{S} 11<-10 \mathrm{~dB}$. This covers theLTE and UWB range of frequency.The radiation pattern and gain is obtained for the resonant frequencies. The impedance bandwidth at the resonances is found in the range from $3 \%$ to $6 \%$.In the later part of the paper an equivalent circuit model of this configuration is designed using the NI AWR software environment. The results obtained from the HFSS analysis and circuit model are tested using Vector Network Analyser. A good matching is observed. The heptafrequency response of a single element antenna is suitable for Wireless communication,Intelligent Transportation System (ITS),WiMAX, Wi-Fi, RFID, ISM band applications, etc.

\section{DESIGN METHODOLOGY}

In this design primarily a circular patch of radius $a$ is chosen as given in Fig.1 (a) for resonance at $6 \mathrm{GHz}$ as per the basic formula [32]

$$
f_{r}=\frac{x_{m n}^{\prime} C}{2 \pi a \sqrt{\varepsilon_{r}}}
$$

Here $\mathrm{x}_{\mathrm{mn}}^{\prime}=1.81$ for $\mathrm{TM}_{110}$ mode, $\mathrm{c}=3 \times 10^{8} \mathrm{~m} / \mathrm{sec}$, $\varepsilon_{r}=4.4$ for FR4_epoxyand $f_{r}=6 \mathrm{GHz}$, the resonating frequency and $a=9 \mathrm{~mm}$, the radius of the circle. The authors implemented the concept of Apollonian gasket and Soddy's circle to taper the three edges of the circular patch and cutting a inner circular slot as shown in figure 1(a).The edges are cut using the periphery of the Apollonian circles namely A,B \& C [Figure1 (a)]. D \& E are the outer and inner Soddy circle respectively. The radius(s) of the circle $E$ is obtained by using the

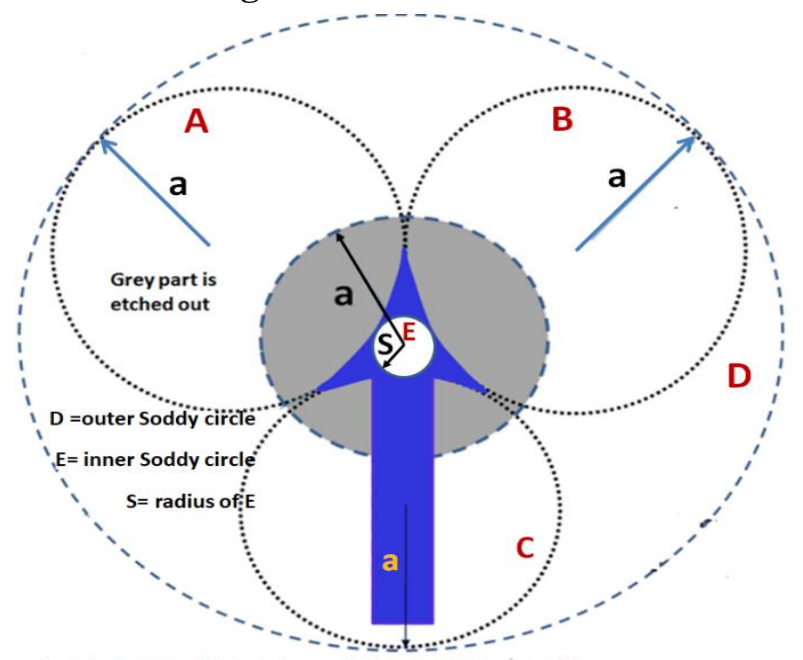

(a)

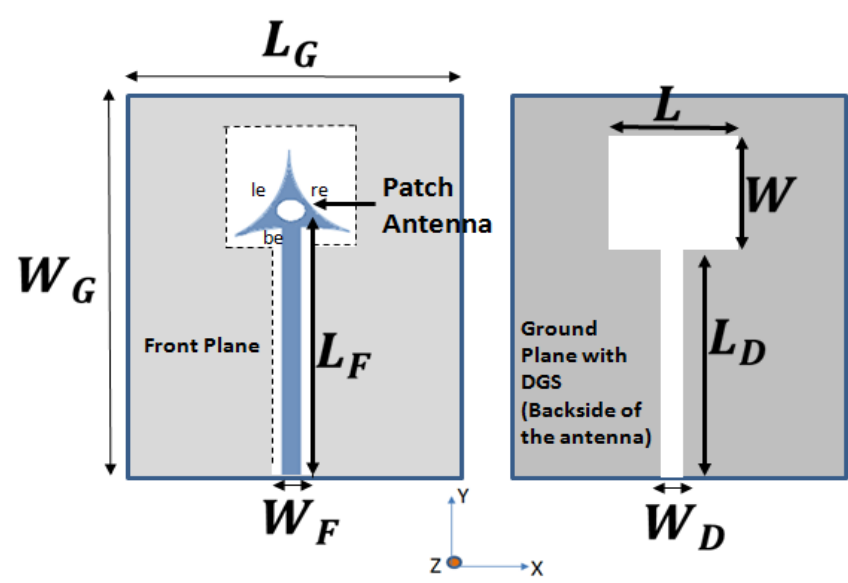

(b)

Figure 1. (a) basic design procedure to implement slots on the patch(b) Proposed microstrip patch antenna concept of Soddy's inner circle. The radii of both outer and inner Soddy circles can be found by using the formula given by Frederick Soddy [26]

$$
r_{4}^{ \pm}=\frac{r_{1} r_{2} r_{3}}{r_{1} r_{2}+r_{1} r_{3}+r_{2} r_{3} \pm 2 \sqrt{r_{1} r_{2} r_{3}\left(r_{1}+r_{2}+r_{3}\right)}}(2)
$$

Here $r_{1}, r_{2}, r_{3}$ are the radii of the 3 mutually tangent circlesand $r_{4}{ }^{+}$is the radius of the inner and $r_{4}{ }^{-}$is the radius of outer Soddy circles. In our case we have taken $r_{1}=r_{2}=r_{3}=a$ and $r_{4}^{+}=s$. Under this assumption we get,

$$
S=\frac{a^{3}}{3 a^{2} \pm 3.4 a^{2}}
$$

The peripheral cuts and the slot at the patch centre andthe DGS at the bottom ground plane introduce multiple resonances.

\section{RESULTS AND PARAMETRIC STUDY}

The simulation of the configuration shown in Figure 1 is performed using Ansoft HFSS software. 
The patch antenna with DGS gives a multiband heptafrequency response at resonant frequencies $1.17 \mathrm{GHz}, 3.44$ GHz, $6 \mathrm{GHz}, 8.1 \mathrm{GHz}, 9.5 \mathrm{GHz}, 11.8 \mathrm{GHz} \& 13.5 \mathrm{GHz}$ with S11 of $-17 \mathrm{~dB},-21 \mathrm{~dB},-16 \mathrm{~dB},-28 \mathrm{~dB},-43 \mathrm{~dB},-20 \mathrm{~dB}$ \& $-15 \mathrm{~dB}$,respectivelyin the frequency range from $1 \mathrm{GHz}$ to $14 \mathrm{GHz}$ as shown in Figure 2. The measured impedance bandwidths for $\mathrm{S} 11<-10 \mathrm{~dB}$ are50 $\mathrm{MHz}(1.14 \mathrm{GHz}-1.19$ GHz), $200 \mathrm{MHz}(3.38 \mathrm{GHz}-3.58 \mathrm{GHz}), 210 \mathrm{MHz}(5.84$ GHz-6.05 GHz), $200 \mathrm{MHz}(7.93 \mathrm{GHz}-8.13 \mathrm{GHz}), 250$ MHz (9.35 GHz-9.6 GHz),430 MHz (11.39 GHz-11.82 GHz), and $500 \mathrm{MHz}$ (13.29 GHz-13.79 GHz). The measurements are done using Agilent Vector Network Analyser. The simulated and measured results are found in good agreement as shown in Figure2.A little mismatch between the simulated andmeasured results may be due to soldering effect or fabrication, and SMA connector losses. The highest gain achieved by the antenna is $1.9 \mathrm{dBi}$.

Following parametric study is done to see the effects of different dimensions of configuration on antenna performance.

III.AThe effect of the radius of inner circular: The inner circle radius(s) affects the resonant frequencies to a great extent. The circular slot introduces capacitive effects on the radiating patch. Hence change in the dimension of the circular slot results in the change of resonant frequency peak.

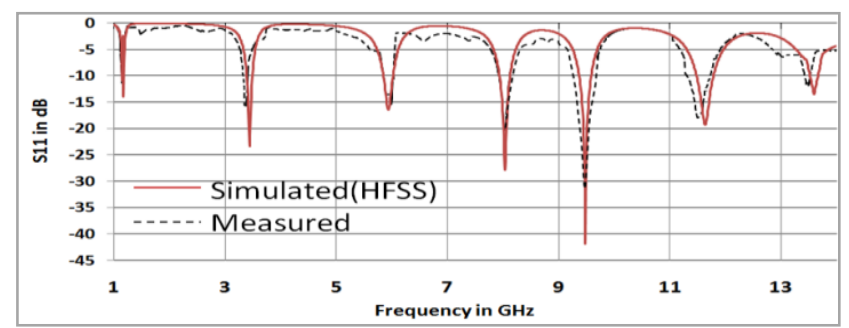

Figure2: Simulated and measured $S_{11}$ vs.frequency for the antenna

Figure 3 shows the S11vs.frequency plot for different inner circle radius. It can be observed that with the increase in the radius of the inner circle the resonant frequency tends to shift towards the right i.e. if the circle radius is increased resonant frequencies also increase. Through curve fitting and iterative technique the relation between resonant frequencies and inner circle radius is found and are expressed below:

Table I: Antenna parameter (All dimensions are in $\mathbf{~ m m}$ )

\begin{tabular}{|l|l|l|l|l|l|l|l|l|}
\hline $\boldsymbol{L}_{\boldsymbol{F}}$ & $\boldsymbol{W}_{\boldsymbol{F}}$ & $\boldsymbol{S}$ & $\boldsymbol{L}_{\boldsymbol{G}}$ & $\boldsymbol{W}_{\boldsymbol{G}}$ & $\boldsymbol{L}$ & $\boldsymbol{W}$ & $\boldsymbol{L}_{\boldsymbol{D}}$ & $\boldsymbol{W}_{\boldsymbol{D}}$ \\
\hline 26 & 3.03 & 1.2 & 38 & 40 & 10 & 12 & 23 & 4 \\
\hline
\end{tabular}

$f_{1}=-1.1 s+2.47$

$f_{2}=-1.1 s+4.83(4 \mathrm{~b})$

$f_{3}=-1.6 s+7.87$

$f_{4}=-0.97 s+9.19(4 d)$

$f_{5}=-0.9 s+10.57$

$f_{6}=-0.9 s+12.62$

$f_{7}=-1.37 s+15.31$

Fromthe above analysis the final dimension of $s$ is selected to be $1.2 \mathrm{~mm}$ for best performance which also agrees well with the value obtained from the Soddy's equation (2)

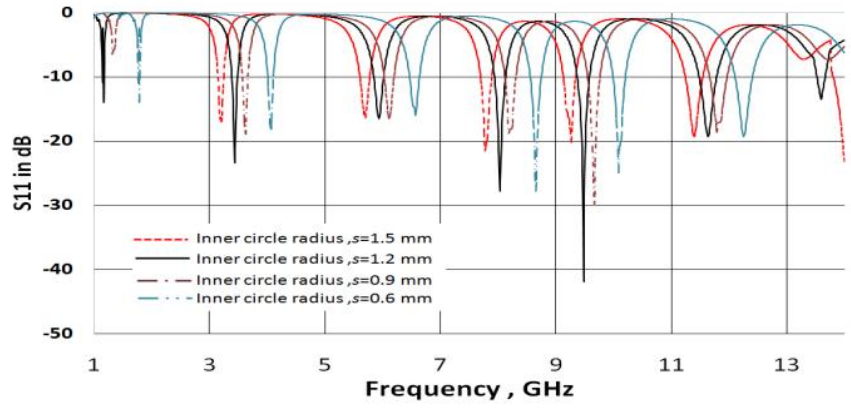

Figure 3: Simulated and measured $S_{11}$ vs. frequency for different inner circle radius

III.BThe effect of DGS design parameters:Figure4 shows the $S_{11}$ response vs. frequency for different DGS window size. It has been observed that with the change in the size of window shaped DGS the higher resonant frequencies gets shifted though the lower resonance frequencies $(<6 \mathrm{GHz})$ remain the same. The etching of the window shaped defect on ground plane induces reactive elements to the ground which affects the higher resonating frequencies mostly. The final dimension of the WDGS is selected to be $10 \mathrm{~mm}$ x 12 $\mathrm{mm}$ for optimum performance.

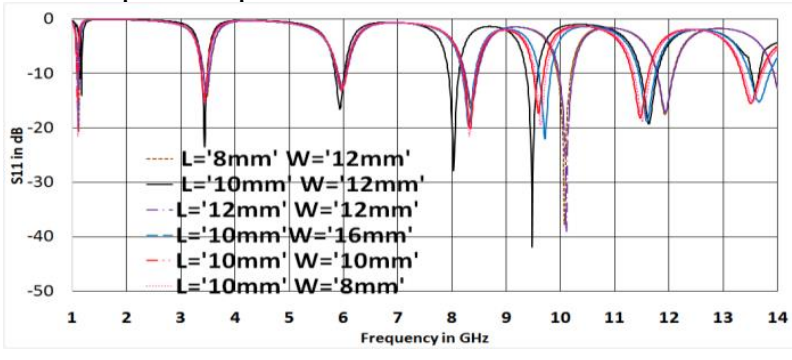

Figure 4: Simulated and measured $S_{11}$ vs. frequency for different WDGS $(L=10 \mathrm{~mm}, W=12 \mathrm{~mm})$

From the above parametric study the design configurations are finalised and shown in Table I. The optimised performance of the antenna is given in table II.

Table II: Optimised performance of the proposed antenna

\begin{tabular}{|c|c|c|c|c|c|c|c|}
\hline $\begin{array}{c}\text { Frequenc } \\
\text { y in GHz }\end{array}$ & 1.17 & 3.4 & 6 & 8.1 & 9.5 & 11.8 & 13.5 \\
\hline S11 & -17 & -21 & -16 & -25 & -33 & -20 & -14 \\
\hline $\begin{array}{c}\text { Bandwidt } \\
\text { h in \% }\end{array}$ & 6 & 6 & 3 & 4 & 3 & 3 & 3 \\
\hline $\begin{array}{c}\text { Gain(Ma } \\
\text { x) }\end{array}$ & \multicolumn{10}{|c|}{$1.9 \mathrm{dBi}$} \\
\hline $\begin{array}{c}\text { Applicati } \\
\text { ons }\end{array}$ & \multicolumn{10}{|c|}{ LTE/WiMAX } & $\begin{array}{c}\text { Radar Communication / } \\
\text { wireless Communication }\end{array}$ \\
\cline { 2 - 6 } & \multicolumn{3}{|c|}{ UWB applications } & \\
\hline
\end{tabular}

Figure 5 shows the radiation pattern of the antenna for all the seven resonant frequencies. The antenna radiation pattern at different resonance frequencies are shown in Fig 5. Broadside radiation characteristic is found at all frequencies. 
A Multiband Arrow Shaped Patch Antenna Based on Apollonian Gasket and Soddy's circle for application in LTE and UWB range

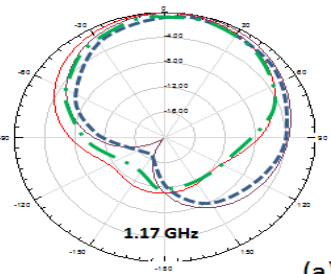

(a)
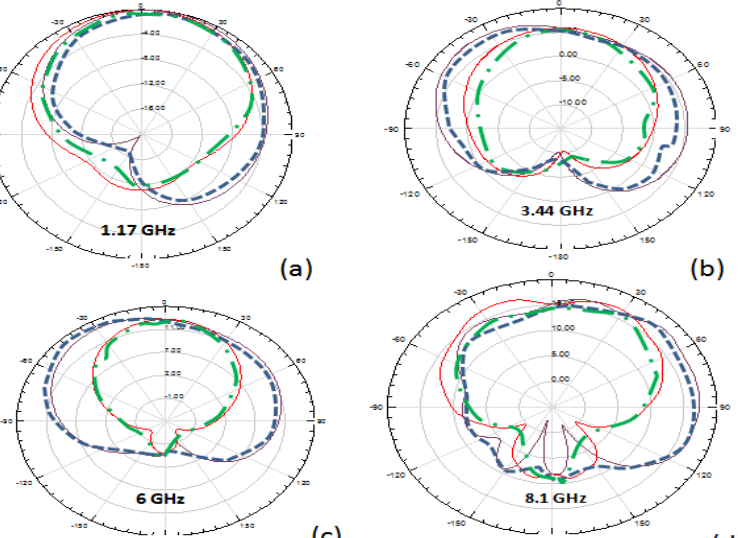

(c)

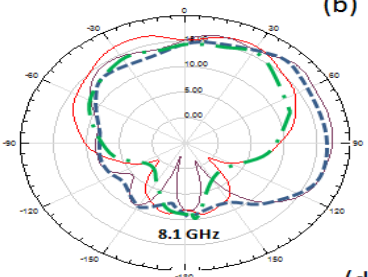

(d)
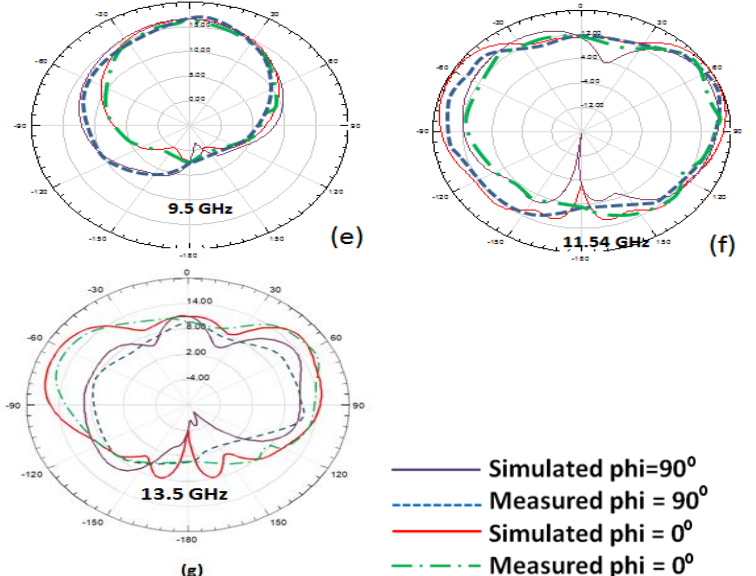

Figure 5: The radiation pattern of the proposed structure at (a).1.17GHz (b.) 3.44. GHz (c.) 6GHz (d.)8.1 GHz (e) 9.5 GHz (f) 11.54 GHz (g) 13.5 GHz

\section{III.C. SURFACE CURRENT DISTRIBUTION}

The distribution of surface current density helps in better understanding of the performance of proposed antenna. Figure 6(a) shows the top surface current density and bottom conductors of the antenna configuration which is obtained using HFSS simulation for excitation at resonant frequencies 1.17, 3.4, 6, 8, 9.5, 11.8 and $13.5 \mathrm{GHz}$.The ground plane defectschange the current distributions. The components of current that are parallel to the edge of the defect cause an inductive effect and the components perpendicular to the edges produces capacitive effect.

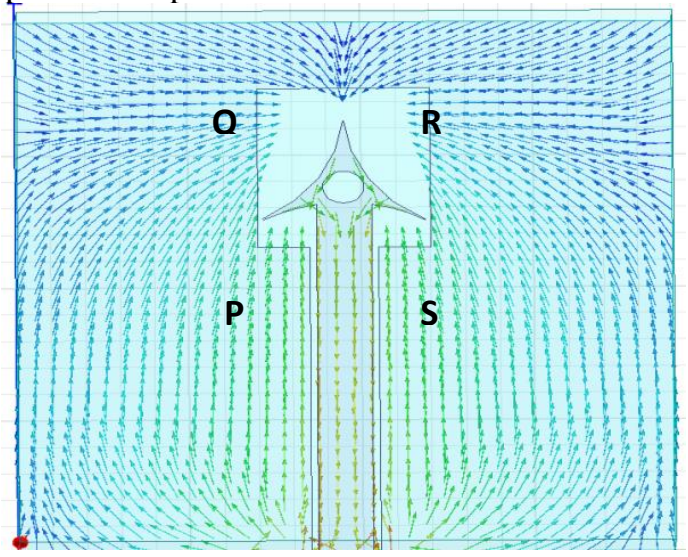

$1.17 \mathrm{GHz}$

(a)

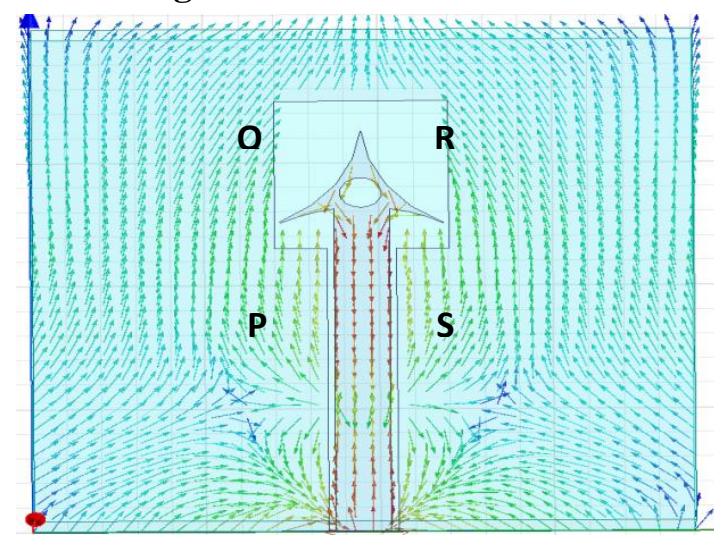

$3.44 \mathrm{GHz}$

(b)

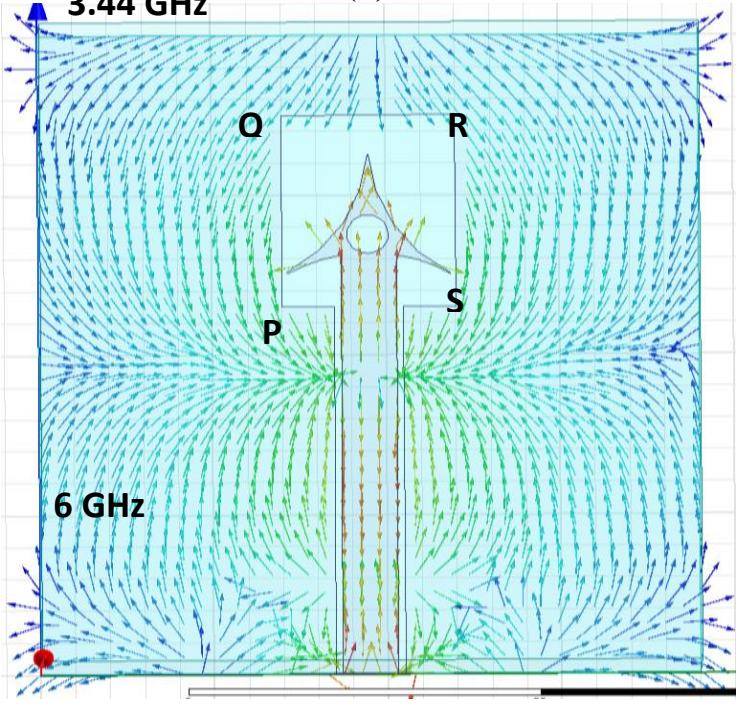

(c)

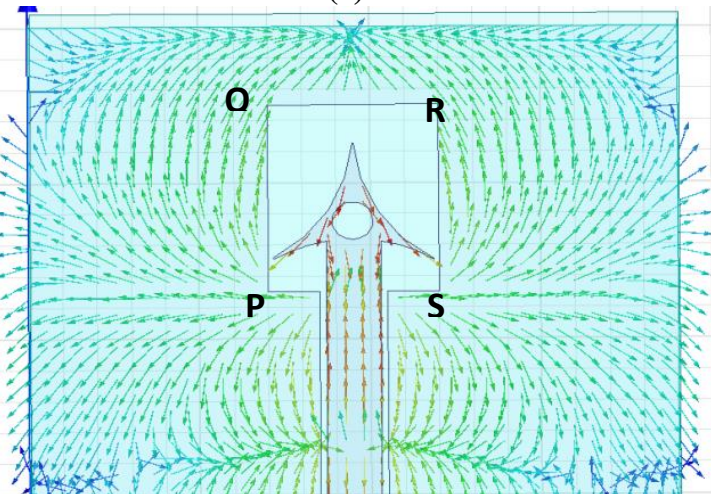

$8.1 \mathrm{GHz}$

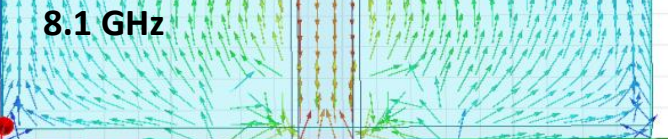

(d) 


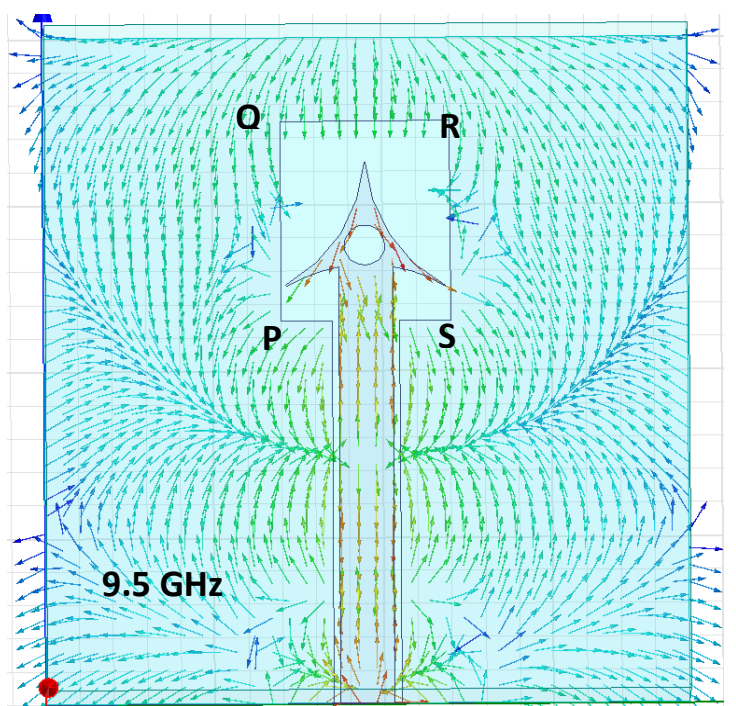

(e)

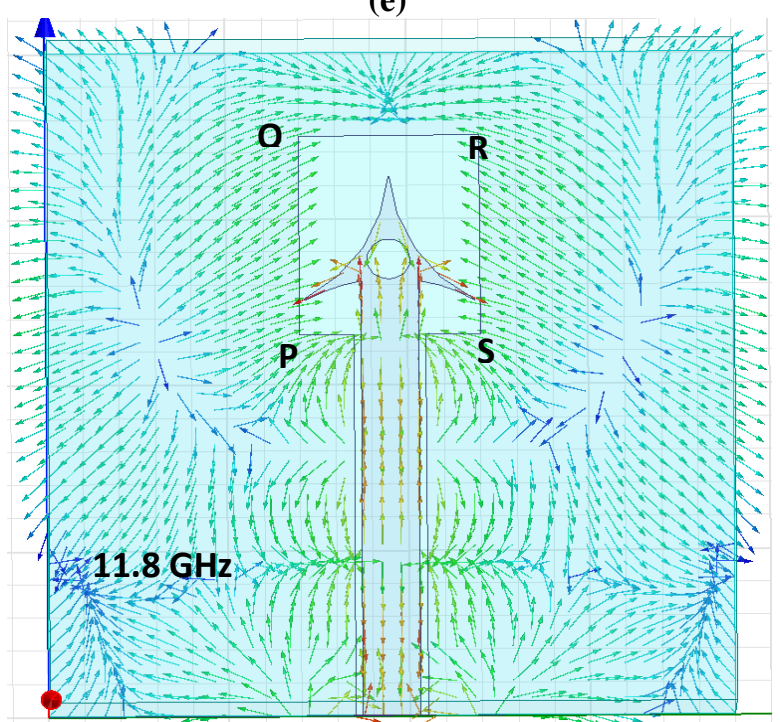

(f)

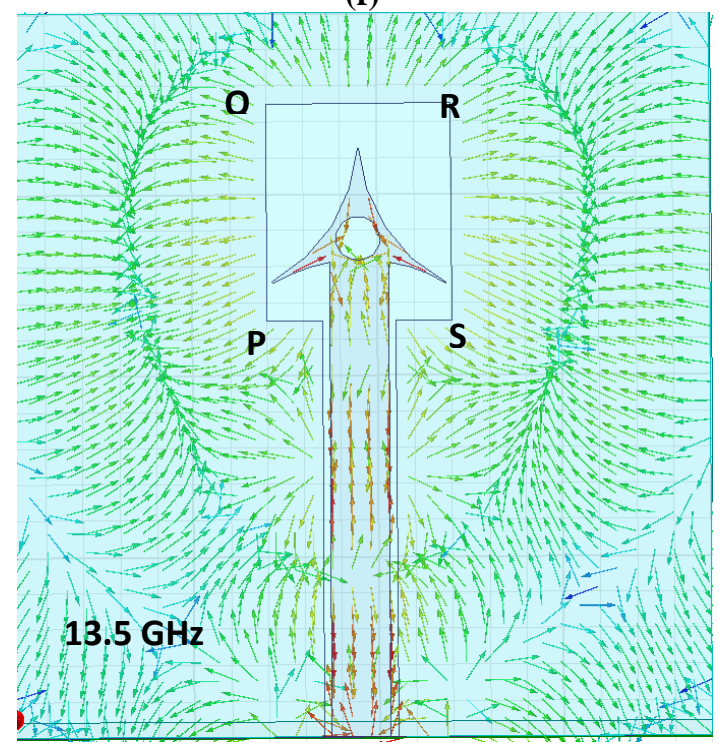

(g)

Figure 6: current distribution on the surface of the patch for different frequencies(a) 1.07GHz(b) 3.44GHz (c) 6 GHz (d) 8.1 GHz. (e) 9.5GHz (f) 11.8GHz (g) 13.5GHz

It is seen that the current density is higher on the feed line and around the lower half of the DGS for the resonant frequency at $1.07 \mathrm{GHz}$ and $3.44 \mathrm{GHz}$. As thefrequency increases thecurrent gets more intense towards the edges of the patch. At $6 \mathrm{GHz}$ current density at both the edges ' $l e^{\text {' }}$ (left edge)and're' (right edge) are high. For $8.1 \mathrm{GHz}$ the concentration is higher towards're'. The current density gets concentrated towards the bottom edge 'be'of the patch at resonance frequency $9.5 \mathrm{GHz}$. Again at $11.8 \mathrm{GHz}$ and 13.5 $\mathrm{GHz}$ the superficial current density is higher at all the edges of the patch and around the whole structure of DGS. From the above observation it can be concluded that the lower half of the DGS affects the lower frequencies more than the upper half of the DGS window. As the resonant frequency increases the circular slot on the patch and the whole structure of DGS on ground plane starts to influence the frequency response of the antenna.In Figure 6-a., the intersection of current at the upper part of PQ and RS edges of DGS is perpendicular giving rise to capacitive effect. At the lower part of side surfaces QP and RS of Defective Ground Structurethecurrent distribution is predominantly parallel causing an inductive effect. The combined result produces a resonance at $1.07 \mathrm{GHz}$. At $3.44 \mathrm{GHz}$ (Figure 6b) same effect observed with stronger distribution of currents resulting in additional resonance. In Figure 6-c the current distribution changes direction causing capacitive effect at the edges PS \& QR and inductive effect at the edges PQ \& RS, causing resonance at $6 \mathrm{GHz}$. In Figure 6-dit can be observed that the superficial current around the defect causes predominantly inductive effect with little capacitive effect at the top edges.In Figure 6-e again the edges PS \& QR give rise to capacitive effect and the upper edges of $\mathrm{PQ} \& \mathrm{RS}$ give inductive effect resulting in additional resonance at $9 \mathrm{GHz}$. In Figure 6-f it is seen that the side edges PQ and RS store electric energy giving rise to capacitive effect while the horizontal edges PS \& QR current causes an inductive effect giving rise to resonance at $11.09 \mathrm{GHz}$. All around the defect in figure 6-g, current distribution shows strong capacitive effect with some weak inductive component giving rise to resonance at $13.5 \mathrm{GHz}$. The circular opening on the patch modifies the current dispersal and trap electric fields, giving rise to capacitive effect. The outward current around the edges of the patch causes an inductive effect. The DGS and the patch with circular slot produce multiple resonances at seven frequencies mentioned above.

\section{DEVELOPMENT OF COMPARABLE CIRCUIT FOR THE PROPOSED ANTENNA}

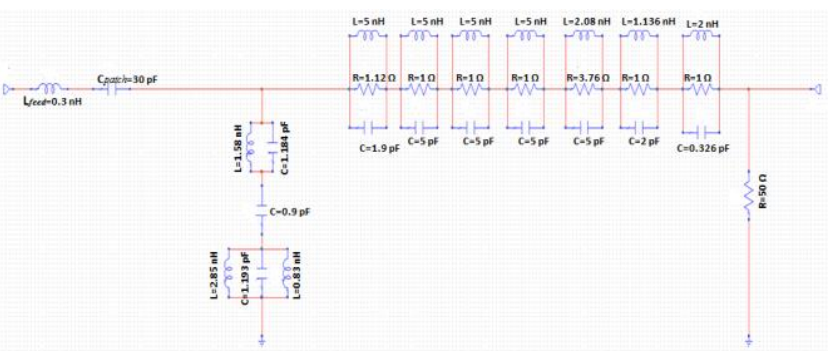

Figure 7: The equivalent circuit of the proposed antenna Ancomparable circuit of the proposed antenna is constructed using NI AWR software environment as shown in Figure 7. In this circuit $\mathrm{L}_{\text {feed }}$ represents the feed line inductance and $\mathrm{C}_{\text {patch }}$ is the antenna capacitance.

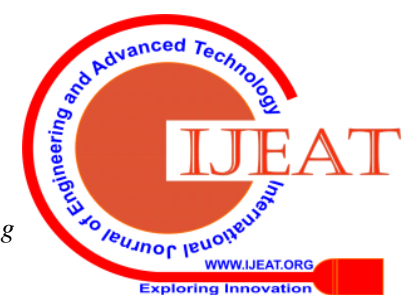




\section{A Multiband Arrow Shaped Patch Antenna Based on Apollonian Gasket and Soddy's circle for application in LTE and UWB range}

Thediscrete RLC element signifies each resonant frequency. The final values are obtained by optimising the value in NI AWR circuit simulation software to match the resultsfound from HFSS simulation as shown in Figure 8.

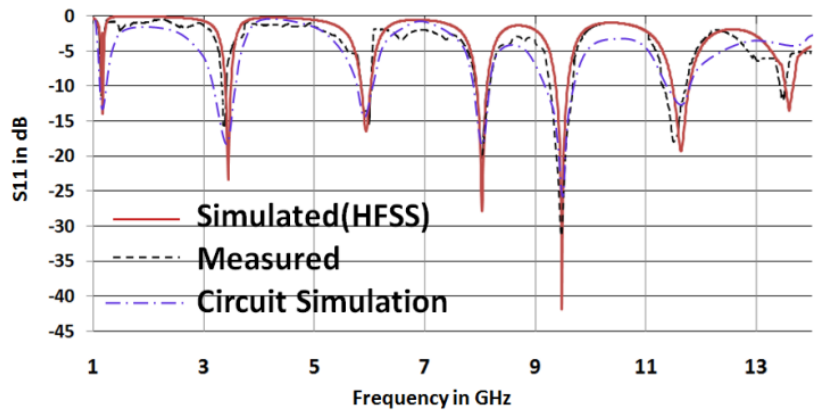

Figure 8: Comparison of $S_{11}$ responses found from HFSS simulation, Circuit simulation and Measurement

\section{EXPERIMENTAL SET UP}
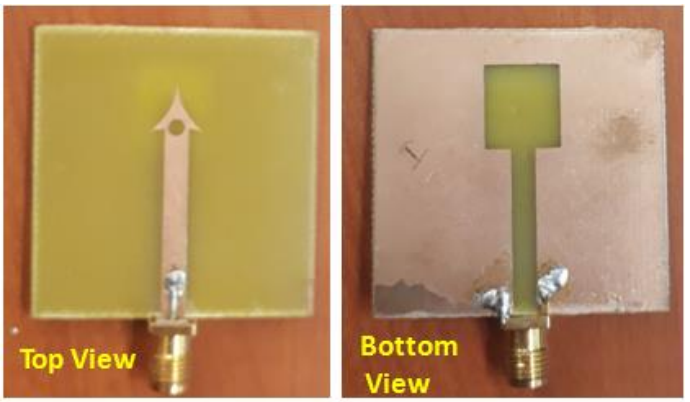

(a)

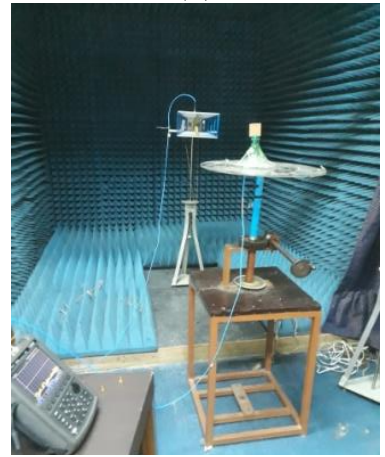

(b)

Figure 9: (a) Hardware of the proposed structure (b) Experimental set up of the

Figure 9 (a-b) shows the hardware of the patch antenna and experimental set up. The return loss and radiation pattern is measured with a Vector Network Analyser. Table III shows the performance of the proposed antenna in comparison with those reported by others. The present antenna performs better in terms of multiple resonances and increased application area.

Table III. Evaluation between the proposed antenna and other published works

\begin{tabular}{|c|c|c|c|c|c|}
\hline $\begin{array}{l}R \\
\text { ef }\end{array}$ & $\begin{array}{l}\operatorname{Size}(m \\
\left.m^{3}\right)\left(\varepsilon_{r}\right)\end{array}$ & $\begin{array}{l}\text { Resona } \\
\text { ting } \\
\text { Freq( } \\
\text { GHz) }\end{array}$ & $\begin{array}{l}\text { OperatingBa } \\
\text { nd(GHz) }\end{array}$ & $\begin{array}{l}\text { No.of } \\
\text { Band } \\
\text { s }\end{array}$ & $\begin{array}{l}\text { Applications } \\
\text { covered }\end{array}$ \\
\hline 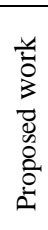 & $\begin{array}{l}38 \times 40 \\
\times 1.6 \\
\left(\varepsilon_{\mathrm{r}}=4.4\right)\end{array}$ & $\begin{array}{l}1.17, \\
3.44, \\
6,8.1, \\
9.5 \\
11.8,13 \\
.5\end{array}$ & $\begin{array}{l}(1.14-1.19),( \\
3.38- \\
3.58),(5.84- \\
6.05), \quad(7.93- \\
8.13), \quad(9.35- \\
9.6),(11.39- \\
11.82), \\
(13.29-13.79)\end{array}$ & $\begin{array}{l}\text { Hepta } \\
\text { band }\end{array}$ & $\begin{array}{l}\text { LTE/WiMAX, } \\
\text { WLAN, } \\
\text { ITS,Wi-Fi, } \\
\text { RFID, IEEE } \\
802.11 \mathrm{a}, \text { ISM } \\
\text { band }\end{array}$ \\
\hline
\end{tabular}

A compact Arrow shaped MPAis designed using the concept of Apollonian Gasket and Soddy's circle with a window shaped defected ground structure and fabricated on FR4_epoxy substrate for Wireless communication, WiMAX, Wi-Fi, RFID, ISM band applications. Seven resonant frequencies are obtained by optimising the design parameters which covers the IEEE $\mathrm{L} / \mathrm{S} / \mathrm{C} / \mathrm{X} / \mathrm{K}_{\mathrm{u}}$-band. The design parameters of the DGS are optimised to get better impedance matching for all the seven frequencies. The resonant frequency and impedance matching are highly influenced by the DGS position and window design parameters. The antenna performance also gets affected by the circular slot on the patch. An equivalent circuit model is designed and reported. The response of the fabricated antenna shows good matching with the simulated structure and yields reasonable gain ( 1 to $2 \mathrm{dBi}$ )which makes it suitable for wireless applications.

\section{ACKNOWLEDGEMENT}

The authors would like to acknowledge the Department of Electronics \& Telecommunication Engineering, Jadavpur University for providing their Laboratory facility for the measurement of the antenna.

\section{REFERENCES}

1. CS.-Kim, JS Park, DAhn, and JBLim, “A novel 1-D periodicdefected ground structure for planarcircuits,"IEEEMicrowaveWirelessComponents Letters, vol10 no4, Apr2000.

2. Robert.Mark, Nipun.Mishra, Kaushik.Mandal, ParthaPratim Sarkar, SomaDas, "Hexagonal ring fractal antenna with dumb bell shaped defected ground structure for multiband wireless applications," AEUE-International Journal of Electronics and Communications, Vol 94, Pp 42-50, June 2018.

3. Biswas P, De S, Bag B, Chanda Sarkar D, Biswas S, Sarkar PP. "Dual ISM band printed antenna with omnidirectional radiation pattern and better radiation efficiency" Int J RF Microw Comput Aided Eng. 2019; e.21780.$$
\text { es Publication }
$$ 
4. KetavathKumar

Naik

PasumarthiAmala VijayaSri,"Design ofHexadecagon

and

"Progress In Electromagnetics Research M, Vol. 63, , 2018"

5. Riki Patel*, Arpan Desai, and Trushit Upadhyaya An Electricaly Small Antenna Using Defected Ground Structurefor RFID, GPS and IEEE $802.11 \mathrm{a} / \mathrm{b} / \mathrm{g} / \mathrm{s}$ Applications Progress In Electromagnetics Research Letters, Vol. 75, 75-81, 2018

6. Beigi P.; Nourinia J: A Novel Printed Antenna with Square Spiral Structure for WiMAXandWLAN Applications, ACES JOURNAL, 2015; 30; 1329-1333.

7. Beigi P.; Mohammadi P: A novel small triple-band monopole antenna with crinkle fractal-structure, Int Journal ElectronCommun (AEÜ), 2016; 70; 1392-87.

8. Beigi P.; Nourinia J.; Zehforoosh Y.; Mohammadi B: A compact novel CPW-fed antenna with square spiral patch for multiband applications , Microwave OptTechnol Lett, 2015; 57; 111-115.

9. Abutarboush H F, Nasif HNilavalanR, Cheung W: Multiband and Wideband Monopole Antenna for GSM900and Other Wireless Applications, IEEE Antennas Wireless Propag Lett, 2012; 11; 539542.

10. Yaxiu Sun, Tingting Guo, Xiaomeng Wang, and Ruiying Sun The Design for Multi-frequency Microstrip Antenna Based on Gap-coupled 2016 Progress In Electromagnetic Research Symposium (PIERS), Shanghai, 8-11 August

11. R. Kiruthika and T. Shanmuganantam* Design and Measurement of Novel Dual Band microstrip Patch Antenna for Radar Applications International Journal of Advances in Microwave Technology (IJAMT) Vol. 2, No 3, August 2017

12. Mukesh Kumar Khandelwal, Binod Kumar Kanaujia, and Sachin KumarDefected Ground Structure: Fundamentals, Analysis, and Applications in Modern Wireless Trends Hindawi International Journal of Antennas and Propagation Volume 2017, Article ID 2018527

13. Humberto C. C. Fernandes, José L. da Silva and Almir Souza e S. Neto"Multi-frequency Microstrip Antenna Using Defected Ground Structures With Band-NotchedCharacteristics xxxv simpósiobrasileiro de telecomunicações e processamento de sinaissbrt2017, 3-6 de setembro de 2017, sãopedro, sp

14. R.Er-rebyiy,. JZbitou,ATajmouati, M.Latrach, A.ErrkikL.El Abdellaoui1 “A New Design of a MiniatureMicrostripPatchAntenna Using Defected Ground Structure DGS

15. Singh,AK., Gangwar, RK. and Kanaujia, BK (2016), Sectored annular ring microstrip antenna with DGS for circular polarization. Microw. Opt. Technol. Lett., 58: 569-573. doi:10.1002/mop.29615

16. A. Nagpal, S. S. Dillon, and A. Marwaha, "Multiband EShapedFractal Microstrip Patch Antenna with DGS WirelessApplications," 2013 5th International Conference on CICN, Sep. 2013.

17. Raj, VDhana et al. "Implementation of printed microstrip apollonian gasket fractal antenna for multi- band wireless-applications.” 2015 International Conference on SPCES (2015): 200-204.

18. Dhana Raj, V \& M. Prasad, A \& Satyanarayana, M \& Prasad, G. (2015). Implementation of printed microstrip apollonian-gasketfractal-antenna for multi band wirelessapplications. 200-204. 10.1109/SPACES.2015.7058248.

19. Kumar, R. and Srikanth, I. (2012), Design of apollonian gasket ultrawideband antenna with modified ground plane. Microw. Opt. Technol. Lett., 54: 1793-1796. doi:10.1002/mop.26977

20. Kumar, R. and Tiwari, A. (2009), Design of Appollian-like-gasketfractal-antenna withCPW-fed. Microw. Opt. Technol. Lett., 51: 2836 2839. doi:10.1002/mop. 24757

21. Neeraj Rao , Dinesh Kumar V. Multiband Smith-Apollonian-GasketFractal Antenna for ITS, WiMAX, STM and Satellite Communication 2015 Loughborough Antennas \& Propagation Conference (LAPC)

22. DebatoshGuha ,SujoyBiswas, and Chandrakanta Kumar Printed Antenna Designs Using DefectedGround Structures: A Review of Fundamentalsand State-of-the-Art Developments-FERMAT

23. Trott, M. The Mathematica GuideBook for Programming. New York: Springer-Verlag,

24. Wells, D. The Penguin Dictionary of Curious and Interesting Geometry. London: Penguin, pp. 3-4, 1991.

25. Andrade,J.S Jr.; Herrmann, H J.; Andrade, RF. S.; 2 and daSilva, L. R."Apollonian Networks: Simultaneously Scale-Free, Smal World, Euclidean, Space Filling, and with Matching Graphs." Phys. Rev. Lett. 94, 01870-1-4, 2005

26. SoddyF. "The Kiss Precise."Nature 137, 1021, 1936

27. KimberlingC. "Triangle Centers and Central Triangles." Cong.Numer. 129, 1-295, 1998

28. mathworld.wolfram.com/SoddyCircles
29. Coxeter,H. S. M."The Problem of Apollonius ." Amer. Math. Monthly 75, 5-15,. 1968

30. Vandeghen, A. "Soddy's Circles and the De Longchamps Point of a Triangle." Amer. Math. Monthly 71, 176-179, 1964.

31. Veldkamp, G. R. "A Theorem Concerning Soddy-Circles." Elem. Math. 21, 15-17, 1966

32. Garg, R. (2001). Microstrip antenna design handbook. Artech house.

\section{AUTHORS PROFILE}

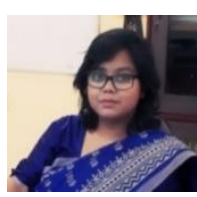

AnurimaMajumdaris currently working as assistant professor in Guru Nanak Institute of Technology, Kolkata. She is pursuing her $\mathrm{PhD}$ in Microstrip Patch antenna. She is a member of IEEE and EMC Engineers (India). She has received grants from UGC for MRPS.

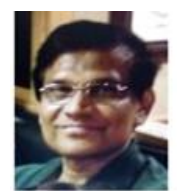

Sisir Kumar Das, Received his PhD degree from Anna University, India. He worked as faculty member in Delhi University (1977-1980). Dr.Das has significant contribution in EMI/EMC evolution and electronics product design. by the industry meeting InternationalStandards\&Electromagnetics Research projects in the country and abroad under the ministryof communication and IT, GOI( 1980-2007). He is currently working as Prof. and Dean Research \& Administration, GNIT, Kolkata. He co-authored two books on microwave engineering and Antenna propagation published by Mc-Graw Hill India. He received society of EMC Engineers (India) highest award 2002 in recognition of his contribution to the EMI/ EMC Solutions for Indian Industrial Products. He is senior member of IEEE, Life member of Society of EMC Engineers (India).

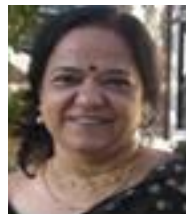

Annapurna Das obtained Ph.D degreein Electrical Engineering from the University of Delhi. She was professor in the Dept. of ECE, Anna University (1985 2007). She was the chief investigator in many research project under GOI. She worked as research fellow under UNDP project of GOI and the Govt. of USA.She coauthored two books on microwave engineering and Antenna propagation published by Mc-Graw Hill India. Presently she is working as Director of GNIT, Kolkata. 